\title{
Research on the Development Orientation of Enterprise Management Incentive Mode under the Background of New Normal and Economic Transformation
}

\author{
Gefei Sun \\ Henan Institute Of Economics And Trade, \\ Zhengzhou, Henan, 450000 China
}

\begin{abstract}
In this paper, we conduct research on the future development orientation of the enterprise management incentive mode under the background of new normal and economic transformation. Along with our country social economy level being unceasing enhancement, the modern enterprise management mode also has corresponding improvement, scientific enterprise management gradually, rationalization. In the modern enterprise management mode, for modern enterprise human resources management has always been the hot spot of the enterprise management problems, under the premise of constantly improve the modern enterprise system, human resource management mode to major change. Enterprise's incentive system is an important part of the modern enterprise system, enterprise management, incentive as measures of effective management to enterprise, is the foundation of the enterprises achieve comprehensive in stimulating the enterprise staff's work enthusiasm that has the enormous role. Our research innovatively proposes countermeasures for the challenges for enhancing the future of enterprise management incentive mode.
\end{abstract}

Keywords- Development Orientation, Enterprise Management, Incentive, New Normal.

\section{Introduction}

In the context of knowledge economy, the enterprises should take knowledge resources as the first production factors, based on the development of economic globalization, to the world as an enterprise product market as comprehensively enhance the value of enterprise itself to deepen the connotation of enterprise and the enterprise culture. In today's society is in the primary stage of the development of knowledge economy, the opportunities and challenges, how to turn challenges into opportunities that become the contemporary enterprise managers primary task.

Knowledge-based enterprises is to use the creation of new knowledge, new technology, with high value-added products, is the enterprise attaches great importance to the innovation and learning, is based on development strategy of intellectual property strategy and knowledge and knowledge to operate as a major development strategy of the enterprise. For knowledge of the knowledge-based enterprises create, use and value-added which is relying on the knowledge staff, the management of knowledge enterprises the particularity of communication than the traditional enterprise management communication, lies in how to solve the problem of the good management of the knowledge staff communication that holds the listed characteristics. (1) Knowledge workers belong to a higher level that is self-management, innovation is also a struggle to realize self-value, compared with the general staff and they have unique values. (2) Knowledge workers compared with the general staff's biggest difference is that general staff is often just passively adapt to the organization and the environment, and the knowledge staff is the most energetic potentials in the enterprise, they tend to have a flexible organization and independent working environment, not only do not want to subject to the object, that constraints on people. (3) Lack of personnel engaged in the work of relevant 
accounting professional, this is at present our country many enterprises in the development of the management accounting is a problem. Management accounting is a skill and the operation skills to the operation of the accounting staff has strict requirements of the job, the whole operating process of a very important impact on the efficiency of the accounting work [1-4].

Informatization of enterprise management can also promote the business process reorganization and promote the optimization of organizational structure, traditional organizational structure in many levels, multi-level and bloated, horizontal communication difficulties, the information transmission distortion, the lack of energy, such as the slow response to changes in the outside world. The rapid development of information technology, fundamentally change the way the organization collection, processing, the use of the information, resulting in a huge change of organization form, promotes the business process reengineering and organization structure of refactoring. Correspondingly, we show the primary components of the enterprise management procedures in figure one.

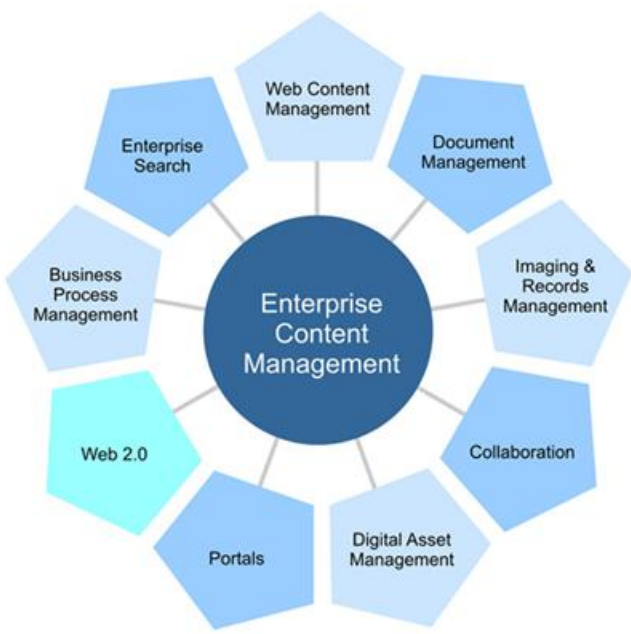

Figure 1. The Primary Components of the Enterprise Management Procedures

In this paper, we conduct research on the future development orientation of enterprise management incentive mode under the background of new normal and economic transformation. A perfect fusion of the knowledge and economic information age of the knowledge economy makes all the traditional enterprise's living environment is changing greatly. In the later sections, we will discuss in detail.

\section{Our Proposed Methodology}

The New Normal. Party politics is the new normal, presents a new current situation that is a kind of different from the past, stable and lasting good politics. We realize in practice, the construction of a new political norm, only from the cadre own quality, organization, discipline, and mechanisms to build effort, grasp the implementation to achieve real results [5].

Regional comprehensive competitive advantage is its location conditions, superior resources and the combination of production factors that is also a region of influence, a combination of the resource allocation and development ability. Advantage is not innate, is accumulated in process of long-term development; Advantage is not set in stone, is a process, the interweavement of dynamic change. In the face of the complicated the development of the market economy, changing the environment, to promote the sustainable and healthy economic and the social development, must constantly find their own new advantages, integrating the existing new advantages, exploiting potential new advantages, using the comprehensive new advantages, drive surface by new advantages of the new breakthroughs in the development of the overall leap. System construction is the basic way of political new normal. Through complete, rigorous system design restricts the use of power, regulate the behavior of politics that can effectively break network, resist the hidden rules, to create a sound political ecology provide strong guarantee. Therefore, we suggest that the characteristics of the new norm could be summarized as the follows. (1) As the central and local things, fiscal, taxation readjustment, the implicit tendency of local government debt as innovated increasingly clear, local government 
debt to leverage. (2) Two-way fluctuation of $\mathrm{RMB}$ exchange rate, foreign exchange systemic decreases the monetary base gap need money to make up for as this makes the central bank for liquidity regulation ability greatly enhanced. (3) With GDP growth is slowing, the internal distribution more and more attention. Look from demographic change, the future allocation will be more conducive to the growth of the laborers remuneration, and operating profit distribution between financial and non-financial companies also deserves attention. (4) Real estate cycle also may have been a turning point for a long period of time. Long period, facing the real estate industry of the endogenous factors began to emerge, these factors include population structure change, super household income growth is the cumulative effect of house prices and the appreciation of the renminbi is expected to weaken and so on.

\section{The Enterprise Staff Management.} Enterprises should make full attention to the occupational health management, positive, and constantly to employee the occupational health management. First, through a variety of health education training or raise the staff awareness on the occupational health management knowledge lectures, to help each employee have a correct understanding and grasps the occupational health management knowledge and ability to cultivate and improve general employee occupational health management. Second, the enterprises should set up relevant occupational health management organizations, to the enterprise management oversight, the physical and mental health of employees through the agency's propaganda and management which make the employees realize the importance of the harm of occupational diseases and occupational health [6].

Trait theory is that the employee's personality is made up of individual character, the character is constitute the basic unit of the personality, decide the behavior of the individual, and personality traits on time has the stability, on the space are universal. Enterprise is the foundation of the people, not to give full play to the individual, not understand how to play a role, individual ability is the enterprise will not be able to become a living organism, and forms the enterprise vitality impossibly. In fact, all the problems of enterprises are based in people, and everyone has his own will. The establishment of enterprise shared vision will focus on individual, personal desire, mind and thinking. If it has not been fully motivate employees, no challenge to the realization of the individual value goal, there will be no growth of enterprises. To fully balance the interests of the individual, personal goal in life, personal interests and aspirations, fully arouse the enthusiasm of each employee, inspire them to the common cause of contribution strength for the enterprise [7].

The Enterprise Management System. Chips are private enterprises should choose management mode of family. Chips are private enterprises, no matter from the scale, tangible or intangible assets are increasing rapidly, the complexity of management at this time will slowly change, in order to cope with the enterprise of the complicated situation, entrepreneurs will hire the professional management and technical personnel from the outside on the operation and management of the enterprises. At this point, entrepreneurs will face the risk of management control in others then take the family enterprise management mode can avoid the existence of this kind of risk which can put the enterprise main management department internal staff as a senior management position. Family management mode is transition mode in the development of enterprise management mode, with the further expansion of the enterprise scale, the internal contradictions between the members of the family will likely cannot adjust, at this point to establish and improve rules and regulations, make the enterprise to the path of institutionalized management. Global business management culture presents condensed 
commonness and individuality of the common development of the new picture.

Again, industrial and commercial enterprises both in China and the United States is well-known, there are a lot of the obscure ordinary industrial and commercial enterprises, and the development of industrial and commercial enterprises between two countries have a quite different, the two countries most of the industrial and commercial enterprises, especially ordinary business has never been in the true sense of the exchanges and cooperation. Culture as a whole in sense of industry and commerce enterprise management should represent the vast majority of industrial and commercial enterprises and the research difficulty cans be imagined. Therefore, we should get focused on the listed aspects of improvements. (1) Promoting knowledge sharing and the learning communication. By advocating knowledge sharing and learning communication, and strive to cultivate knowledge staff willing to communicate between Shared culture, create encourage knowledge staff training and the knowledge sharing mechanism, to fully meet needs of the knowledge staff's personal growth and development. (2) Pay special attention to emotional interactive communication. Interactive communication through positive emotion, foster the sense of belonging and identity of the knowledge-type employees, help to reduce the working pressure of the knowledge-type employees as fully motivate their enthusiasm. (3) Actively expand communication channels, the fusion of enterprise managers and knowledge workers. Because of knowledge-based employees engaged in creative work, its independence, autonomy is strong, more emphasis on enterprise managers must take equal communication and let the knowledge staff can fully express their views, and to respect and accept their advice, communication between the two sides to achieve a win-win situation.

The Enterprise Incentive Methodologies. Incentive is based on the general humanistic theory, people-centered management activities as it is pursuit of humanized management. Mechanism on the inner relationship between the elements within the system known as the foundation, emphasize the rational aspects of human behavior and its pursuit of institutionalized management. The two organic combinations that is the incentive mechanism, also known as the incentive system in the organization system, incentive mechanism is through a rational system to reflect the incentive subject and incentive object interaction. Incentive mechanism once formed, it will effect on internal organization system itself to make the organization function in a certain state, and further affects survival and development of the organization [8].

Incentive mechanism consists of two elements: the first, see what he needs, and then use this thing to finish the work as an employee reward. Second, to determine whether his ability can finish the work, that is to say, needs and abilities are to realize incentive function of two factors. State-owned enterprises in market-oriented factors significantly weaker in southeast coastal area of state-owned enterprises, the southeast coastal areas and the state-owned enterprises in the northeast of the obvious difference is that former market factors have dominated the latter marketization and administrative interference factors are still in a state of American and embedded. Analysis perspective of previous studies mostly incline to the state-owned enterprise as a relatively independent closed the rationality of the main body, to maximize their own interests to adapt to the change of market environment, the research framework more focus on the relationship between the organization and market. Based on this perspective, we propose the enterprise incentive methodologies as follows.

- Enterprise culture is the embodiment of the spirit. Effective incentive can make the enterprise upward, enthusiasm, the pursuit of excellence, such as good 
corporate atmosphere, and to get the support of all staff and external recognition. The excellent enterprise culture is the spiritual source of enterprise long-term development.

- Motivation is to satisfy people's various needs to mobilize the work enthusiasm of the people. Under effective incentive, the employees will be conducted in order to meet the needs of their consciously learning, training, so as to improve their own quality.

- Talent is the backbone of enterprise development, they often profoundly affects management level of enterprises, operating conditions, technical level and development prospects, the brain drain is a great loss to enterprises. Therefore, effective incentives should be particularly focus on for enterprises to attract talented people, and to provide them with broad space for further development to maximize their potential.

- Good motivation will make staff full of enthusiasm, innovative spirit and spirit of cooperation that can improve enterprise staff's overall ability. Performance in production is to improve the production efficiency of enterprises and management benefit.

\section{Conclusion}

In this paper we conduct research on the future development orientation of the enterprise management incentive mode under the background of new normal and economic transformation. Motivation is the original psychological terms, refers to the psychological process of the people's behavior motivation. From the perspective of management, incentive is a function of leadership and management, is refers to leader use all kinds of means, inspire the motivation of subordinates and encourage subordinates give full play to the internal potential, to act in accordance with the requirements for the desired objectives of the process that say simply is to mobilize the enthusiasm of staff. There is no doubt that the establishment of a comprehensive, scientific salary management system, for enterprises in the era of knowledge economy to foster the core competitive ability and competitive advantage, to obtain the sustainable development of enterprises is of great significance. Our research starts from analyzing the corresponding issues to propose the new idea which is innovative.

\section{References}

[1] Cui, Songyan, and Anfeng Xu. "An Approach to Evaluating the Enterprise Management Information System with Intuitionistic Fuzzy Information." International Journal of Advancements in Computing Technology 4.4 (2012).

[2] Lobo, Sanjay, et al. "Systems and methods for enterprise management using contextual graphs." U.S. Patent Application No. 14/506,524.

[3] Liu, Feipeng. "Plights and Solutions of Enterprise Human Resource Management." 2014 International Conference on Education, Management and Computing Technology (ICEMCT-14). Atlantis Press, 2014.

[4] Chen, Peng. "Enterprise Technology Innovation Capability Evaluation Based on Knowledge Management." Computational Sciences and Optimization (CSO), 2014 Seventh International Joint Conference on. IEEE, 2014.

[5] Chen, Feifei. "Primary Investigation on reform of post practice mode based on school-enterprise collaborative innovation." 2014 International Conference on Education Technology and Social Science. Atlantis Press, 2014. 
[6] Zhang, Xianzhi. "Management Control Elements and Management Control System." Enterprise Management Control Systems in China. Springer Berlin Heidelberg, 2014. 143-150.

[7] Shaul, Levi, and Doron Tauber. "Critical success factors in enterprise resource planning systems: Review of the last decade." ACM Computing Surveys (CSUR) 45.4 (2013): 55.

[8] Feng, Na, et al. "Research on Activity-based Costing Management Platform for Coal Enterprise." Coal Mine Machinery 2 (2013): 138. 